\title{
Sexual adjustment after spinal cord injury-comparison of partner experiences in pre- and postinjury relationships
}

\author{
M Kreuter MSc PT, ${ }^{1}$ M Sullivan PhD ${ }^{2}$ A Siösteen RPT, $\mathrm{PhD}^{1}$ \\ ${ }^{1}$ Spinal Injuries Unit and ${ }^{2}$ Health Care Research Unit, Sahlgrenska University Hospital, \\ S-413 45 Gothenburg, Sweden.
}

This study compared the emotional and sexual aspects of relationships before and after spinal cord injury, from the partner's point of view. In addition, the personality characteristics of the partners were investigated. Twenty-six relationships were established before the injury and 23 after. The couples in preinjury relationships had been married or cohabiting for 3.5-51 years (median 24 years), while postinjury relationships ranged from 1 to 8 years (median 2 years). There were substantial differences in age between preinjury and postinjury partners, 21-79 years (median 51 years) and 18-45 years (median 28 years), respectively. Data collection included an 80-item questionnaire, designed to determine different aspects of sexuality, a visual analogue scale Quality of Life (VAS QL) measure and an established inventory of personality characteristics, the Karolinska Scales of Personality (KSP). Eighty-eight per cent of the partners in preinjury and $86 \%$ in postinjury relationships considered their overall relationship to be satisfactory. Concerning the sexual aspects of the relationships, several differences were revealed, all favouring postinjury relationships. Some of these held true even when age was treated as a significant factor and statistically controlled. Although the frequency of sexual activity and the variety of sexual expressions used were lower in the preinjury relationships, and perceived deterioration of sex life due to the injury was higher among preinjury partners, there was no significant difference between the two groups in satisfaction with current sex life. Thus, age seems to be a more important factor for sexual adjustment after a spinal cord injury, rather than whether the relationship is established before or after injury. The partners' personality characteristics differed only slightly from those of a sex and age matched reference group and not at all between partners in pre- and postinjury relationships.

Keywords: spinal cord injuries; sexual adjustment; marital adjustment; sexual partner relationships; personality characteristics; pre- and postinjury relationships.

\section{Introduction}

A satisfying sex life depends on many factors, and some of these will be directly influenced by someone having had a spinal cord injury (SCI). In addition to the physical limitations caused by a SCI, the loss of genital sensation and erectile function, and difficulties with bowel and bladder control interfere with sexual function, body image and self esteem.
The premises in an already existing intimate relationship may be totally altered by an SCI since the injury was something neither partner had considered. The changes imposed by the disability may be difficult for the non-injured partner, as well as for the injured person, to handle. As the disability is known from the beginning in relationships established after injury, there 
may be a better chance of success. Although it may be assumed that the consequences of a SCI will also affect the non-injured partner concerning intimate relationships, relatively little reserach has concentrated on the partner's perception of their marital and sexual life with a SCI person. ${ }^{1,2}$

The extent to which divorce occurs among SCI persons is uncertain. In earlier studies, ${ }^{3,4}$ it was found that preinjury marriages had about the same risk of ending in divorce as marriages in the general population, whereas postinjury marriages were less likely to fail. However, a study of 700 SCI veterans revealed no differences in the divorce rate between pre- and postinjury marriages. ${ }^{5}$

Crewe et $a l^{6}$ compared preinjury and postinjury marriages and found that postinjury marriages could be described as more satisfying compared with preinjury marriages. One-third of the preinjury couples indicated that they were satisfied with having no sexual activity at all, whereas this was reported by only one out of 31 couples in postinjury marriages. The SCI persons in preinjury marriages were less independent and received more help with daily activities from the partner. In a later study, ${ }^{7}$ Crewe et al found that emotional adjustment and satisfaction with sex life were greater in postinjury marriages, even when the effects of age discrepancy were statistically controlled. Further information about the couples' sex life was not given. They concluded that preinjury marriages were burdened by the losses stemming from the SCI. From their findings, they suggested that spouses in postinjury marriages might have unusual qualities or values that contributed to the success of these unions. The study of Simmons and Ball ${ }^{8}$ showed that both husbands and wives in postinjury marriages were more inner-directed and had better marital adjustment compared with those married before the injury.

The purpose of this study was to determine whether there are sexual and emotional differences between preinjury and postinjury relationships from the partner's point of view. A second aim of the study was to investigate if the personality profile differs between partners in preinjury and postinjury relationships or from those in a reference group.

\section{Study group and methods}

\section{Sample and procedure}

As part of a comprehensive study at the Spinal Injuries Unit, Sahlgrenska University Hospital, Gothenburg, the intimate relationships as experienced by the SCI person's partner were studied in a consecutive series of 252 SCI persons. Partners who at the time of the investigation were living in a stable partnership with an SCI person were included in this study. The injured person was to have been living outside the hospital for a minimum of one year. Partners of SCI persons who had recovered (Frankel E) ${ }^{9}$ were excluded.

Two groups of partner relationships were investigated: those that were established before the injury and those that began postinjury.

Both telephone interviews and subsequently mailed questionnaires were used to collect the study data. Informed consent was obtained at the time of the telephone contact, and the purpose of the investigation and the nature of the questionnaires were described.

Completed questionnaires were obtained from 49 partners, giving a response rate of $78 \%$. Twenty-six relationships were established before the injury and 23 had begun after injury. There were substantial differences between the two groups in terms of age and duration of the relationships. At the time of the investigation, the length of preinjury relationships ranged from 3.5 to 51 years (median 24 years). The duration of postinjury relationships ranged from 1 to 8 years (median 2 years). In the preinjury group, 19 were female and seven were male partners, and in the postinjury group 20 were female and three were male partners. Among preinjury partners, age ranged between 21 and 79 years (median 51 years), and postinjury partners ranged in age from 18 to 45 years (median 28 years). The SCI persons in preinjury relationships were equivalent to the postinjury group in terms of levet and completeness of the lesion. 
Table I shows the basic demographic data for the two groups.

\section{Measurement instruments}

Information collected through the telephone interview included physical and sociodemographic data.

\section{Relationship questionnaire}

The questionnaire, comprising 80 items, was developed to assess different dimensions of sexuality (sexual interest, behaviour and satisfaction) and the emotional quality of the relationships (feelings of affection and intimacy, ability to solve problems within the relationship, ability to communicate about sex with the partner, recreational activities engaged in alone, with others and with the SCI partner, and satisfaction with these areas and with the overall relationship). Additional data were included to determine perceived sexual attractiveness and concerns about partner sexual satisfaction.

Table I Descriptive data for SCI persons and their partners in preinjury and postinjury intimate relationships ( $n=49$ couples)

\begin{tabular}{|c|c|c|c|}
\hline & $\begin{array}{l}\text { Preinjury } \\
\text { relationships } \\
\quad(n=26)\end{array}$ & $\begin{array}{l}\text { Postinjury } \\
\text { relationships } \\
\quad(n=23)\end{array}$ & $p$-level \\
\hline Injury level & C3-L4 & C2-L3 & \\
\hline Tetraplegia, (Frankel A, B, C) & $8(31 \%)$ & $10(43 \%)$ & n.s. \\
\hline Tetraplegia, (Frankel D) & $4(15 \%)$ & $3(13 \%)$ & n.s. \\
\hline Paraplegia, (Frankel A, B, C) & $9(35 \%)$ & $5(22 \%)$ & n.s. \\
\hline Paraplegia, (Frankel D) & $5(19 \%)$ & $5(22 \%)$ & n.s. \\
\hline \multicolumn{4}{|l|}{ The SCI persons' age } \\
\hline Median & 53 years & 29 years & c \\
\hline Range & $23-74$ yrs & $20-46$ yrs & \\
\hline Mean (SD) & $50(13.6)$ & $28(6.7)$ & \\
\hline \multicolumn{4}{|l|}{ Age at injury } \\
\hline Median & 46 yrs & 22 yrs & c \\
\hline Range & $18-69$ yrs & $14-39$ yrs & \\
\hline Mean (SD) & $45(13.5)$ & $23(6)$ & \\
\hline \multicolumn{4}{|l|}{ Time since injury } \\
\hline Median & $4 \mathrm{yrs}$ & $6 \mathrm{yrs}$ & n.s. \\
\hline Range & $1-9 \mathrm{yrs}$ & $1-9 \mathrm{yrs}$ & \\
\hline Mean (SD) & $4.7(2.6)$ & $6.4(2.8)$ & \\
\hline \multicolumn{4}{|l|}{ The partners' age } \\
\hline Median & $51 \mathrm{yrs}$ & $28 \mathrm{yrs}$ & c \\
\hline Range & $21-79$ yrs & $18-45 \mathrm{yrs}$ & \\
\hline Mean (SD) & $49(15.4)$ & $28.2(6.9)$ & \\
\hline \multicolumn{4}{|l|}{ Length of relationship } \\
\hline Median & 24 years & 2 years & c \\
\hline Range & $3.5-51 \mathrm{yrs}$ & $1-8$ yrs & \\
\hline \multicolumn{4}{|l|}{ Partner being care giver } \\
\hline Each day & $35 \%$ & 0 & $\mathrm{~b}$ \\
\hline Several times a week & $19 \%$ & $17 \%$ & n.s. \\
\hline Now and then & $8 \%$ & $17 \%$ & n.s. \\
\hline Never & $38 \%$ & $65 \%$ & a \\
\hline
\end{tabular}

$\mathrm{a}=p<0.05$

$\mathrm{b}=p<0.01$ Pitman's permutation test

${ }^{c}=p<0.001$

n.s. $=$ non-significant. 
Items covering sexual interest, activity and satisfaction were designed to be treated as one composite variable, i.e. to meet the criteria of a multi-item scale, the Sexual Interest, Activity and Satisfaction-SIAS Scale. Areas covered, questions, scale points and scores are described in Table II. Throughout the analysis, all variables are reduced to normal with the variance equal to one. Internal consistency, determined by Cronbach's alpha, ${ }^{10}$ was 0.86 and a principal component analysis ${ }^{11}$ confirmed the unidimensionality of the scale. Factor loading on the principal factor, which accounted for $62 \%$ of the variance, ranged between 0.61 and 0.88 . Based on the method of summated ratings, we assumed that responses to items in the scale could be summed without standardisation or weights. Higher scores indicated better sexual adjustment.

Seven items covering sexual expressions used by the couple were treated as one composite variable, the Sexual Behaviour Scale, and seven items relating to emotional intimacy, affection and communication were aggregated accordingly into the Emotional Quality of the Relationship Scale. Factor loading on the principal factor ranged between 0.74 and 0.96 (the Sexual Behaviour Scale) and 0.65 and 0.85 (the Quality of the Relationship Scale). The range of raw scores on the Sexual Behaviour Scale and that for the Emotional Quality of the Relationship Scale were 7-49 and 7-28, respectively. The higher the scores the better.

\section{Qualtiy-of-life recording}

The partners recorded their perception of QL on a 0-100 visual analogue scale (VAS), ${ }^{12}$ the endpoints of which were labelled 'very low' and 'very high'.

\section{Self-reported assessment of personality \\ traits}

The Karolinska Scales of Personality Inventory, KSP, ${ }^{13,14}$ was used to determine the personality characteristics of the partners. It has been proved reliable and valid to

Table II The sexual Interest, Activity and Satisfaction-SIAS Scale

Areas and underlying questions

\begin{tabular}{|c|c|c|c|}
\hline Area & Question & Scale point & Score $^{\mathrm{a}}$ \\
\hline Sexual desire & Is your sexual desire lowered? & From never to very often & $4-1$ \\
\hline Sexual activity & $\begin{array}{l}\text { How often do you and your } \\
\text { partner engage in sexual } \\
\text { activity, with or without } \\
\text { intercourse? }\end{array}$ & $\begin{array}{l}\text { From every other day to } \\
\text { never }\end{array}$ & $8-1$ \\
\hline \multirow[t]{4}{*}{ Sexual satisfaction } & $\begin{array}{l}\text { Do you generally enjoy the } \\
\text { sexual part of your } \\
\text { relationship? }\end{array}$ & From very much to not at all & $4-1$ \\
\hline & $\begin{array}{l}\text { Do you believe that your } \\
\text { partner generally enjoys the } \\
\text { sexual part of your } \\
\text { relationship? }\end{array}$ & From very much to not at all & $4-1$ \\
\hline & $\begin{array}{l}\text { How often would you like to } \\
\text { have sex with your partner? }\end{array}$ & $\begin{array}{l}\text { More often than now } \\
\text { Same as now } \\
\text { Less often than now }\end{array}$ & $3-1$ \\
\hline & $\begin{array}{l}\text { How does your current sex } \\
\text { life compare with your sex } \\
\text { life before your partner's } \\
\text { injury? }\end{array}$ & $\begin{array}{l}\text { From much better to much } \\
\text { worse }\end{array}$ & $5-1$ \\
\hline SIAS scale & Composite of questions & Summary of scale points & $28-6$ \\
\hline
\end{tabular}

aThrough the analysis all variables are normed with the variance equal to one 
measure biologically based personality traits or temperament dimensions that can be regarded as markers for different kinds of vulnerability. ${ }^{13,15-18}$ The questionnaire includes 136 items organised into 15 scales, ten of which are grouped into three main areas: ${ }^{18}$

(1) Anxiety Proneness Scales (psychic anxiety, somatic anxiety and muscular tension).

(2) Extraversion-Related Scales (impulsiveness and monotony avoidance).

(3) Aggression-Hostility Scales (indirect agression, irritability, verbal agression, suspicion and guilt).

The remaining scales are: Psychasthenia; Detachment; Inhibition of Aggression; Social Desirability; and Socialization. The items are statements with a 4-point response format, ranging from stongly disagree to strongly agree. Except for the Socialization (20 items) and Aggression Scales (15 items), all scales consist of 10 items, with higher scores indicating a higher degree of the trait measured. Raw scores are transformed into T-scores (mean 50, SD 10) to allow comparisons across scales. ${ }^{18}$

\section{Statistical methods}

All data were analysed by means of the Statistical Analysis System, SAS. ${ }^{19}$ Standard methodology was applied for construct validation of scaling procedures including the calculation of Cronbach's alpha and principal components analysis. ${ }^{10,11}$ Fisher's non-parametric permutation test was used to test significant differences between groups. ${ }^{20}$ In the comparison of pre- and postinjury relationships, age was analysed as a possible confounder and therefore statistically controlled. A one-way factorial analysis of variance (ANOVA) was performed on the scores of each KSP subscale.

\section{Results}

The emotional quality of the relationship

The majority of partners in both preinjury $(88 \%)$ and postinjury $(86 \%)$ relationships considered their relationship overall to be satisfactory, and all but one preinjury partner felt great or very great affection for their SCI partner (Fig 1). Most of the partners in both preinjury and postinjury relationships ( $87 \%$ and $95 \%$, respectively) were also satisfied with the manner in which problems within the relationship were solved (Fig 1). Eighty-six per cent of the postinjury partners reported that they could easily discuss sex with their injured partner, whereas many partners in the preinjury group $(40 \%)$ thought it was a difficult subject to talk about (Fig 1). One-third of

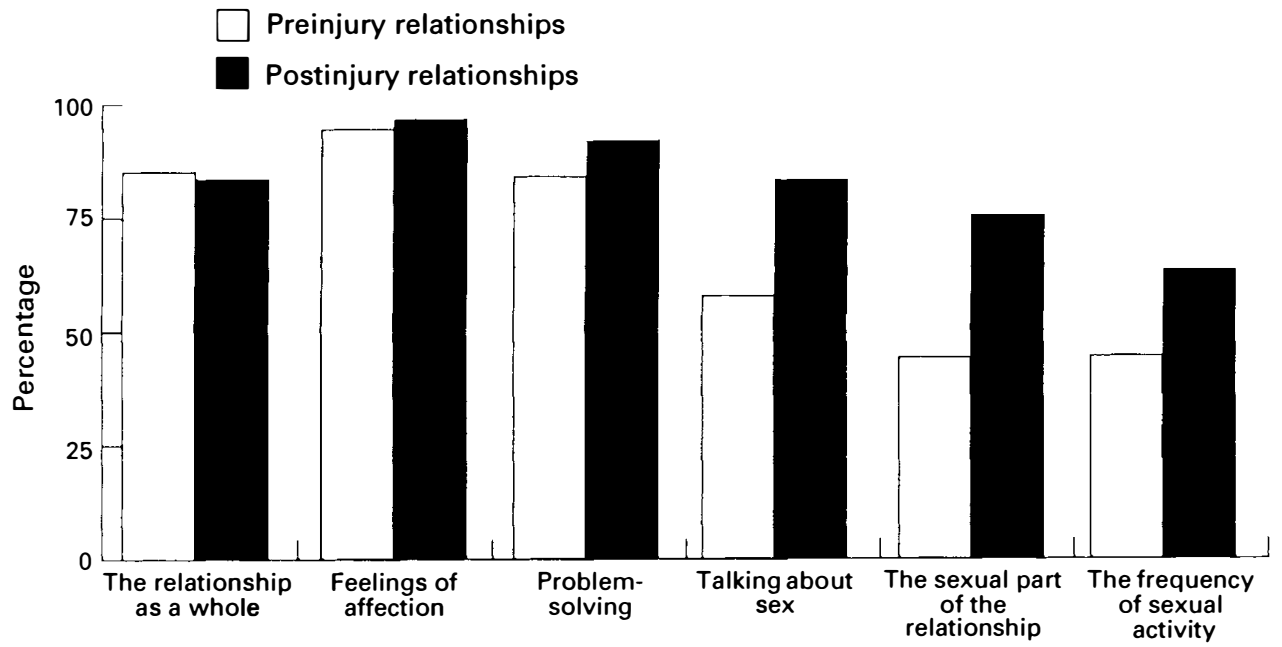

Figure 1 Relative frequency of partners being satisfied with different areas in the relationship ( $n=26$ preinjury and 23 postinjury partners). 
the preinjury partners (36\%) and nearly half of the postinjury partners $(45 \%)$ were engaged in out-of-home activities alone as well as together with their injured partner at least once weekly. Seven preinjury partners claimed that they never had any leisure activities outside the home, either with the partner or alone. A larger proportion of SCI persons in preinjury relationships received regular personal care assistance from their partner $(54 \%$ compared with $17 \%)$. Three partners in preinjury relationships and two in the postinjury group had considered divorce or separation.

Scores on the Emotional Quality of the Relationship Scale for each group are detailed in Table III.

\section{Sexual interest and satisfaction with sexual life}

More than half of the postinjury partners $(59 \%)$ considered themselves to be sexually attractive, whereas only $20 \%$ of partners in the preinjury group had that sense of attractiveness. All but three preinjury partners considered sex an important part of their lives. However, half of the preinjury partners $(46 \%)$ and a quarter of the postinjury partners $(26 \%)$ reported decreased sexual interest due to their partner's injury. Increased interest in sexuality was reported by one partner of each group.

Less than half of the preinjury partners (46\%), but most postinjury partners (78\%), were satisfied with their current sex life (Fig 1). Compared with their previous sex life with a non-injured person, current sex life was considered better by half $(50 \%)$ of the partners in postinjury relationships. Four partners in the postinjury group could not make a comparison because of lack of any previous sexual experience. Three-quarters of the preinjury partners $(77 \%)$ considered that their sex life was now less satisfying compared with the situation before their partner's injury. No-one in the preinjury group thought it was better.

\section{Sexual activity and behaviour}

All couples in the postinjury group were sexually active. Nearly three-quarters $(74 \%)$ of the partners in this group reported sexual interaction once a week or more, with or without intercourse. In the preinjury group, about a quarter of the respondents $(27 \%)$ reported sexual activity once a week or more, whereas infrequent or no sexual activity of any kind was reported by almost half $(46 \%)$ of the partners (Fig 2$)$.

The SCI person's physical limitations and decreased sexual ability were listed as reasons for decreased or diminished sexual activity by nearly two-thirds $(60 \%)$ of partners in preinjury relationships. The same reasons were given by one-third $(32 \%)$ of partners in the postinjury group. Eight preinjury and one postinjury partner claimed that their own decreased sexual desire and unwillingness to engage in sex contributed to diminished sexual interactions.

Almost half $(46 \%)$ of the partners in preinjury relationships were satisfied with the frequency of sexual activity, whereas $42 \%$ expressed a wish to engage in sexual activity more often. Two preinjury partners would have preferred less sexual interaction. In the postinjury group, approximately two-thirds of the partners (65\%) reported being content with the frequency of sexual activity (Fig 1). The remainder in this group (35\%) expressed a wish to engage in sexual activities more frequently.

As illustrated in Figure 3, intercourse and manual and oral stimulation of genitals were commonly part of about a quarter $(23 \%)$ of the preinjury couples' sexual repertoire, whereas the remainder of this group seldom or never used these sexual expressions. Sixty-two per cent of the partners in postinjury relationships reported that they engaged in intercourse every or almost every time they had sex, and manual and oral genital stimulation also became a common part of their sexual repertoire. Manual and oral caressing of other erogenous zones such as the breasts, ears, lips and neck were an important part of the sexual repertoire in most postinjury relationships $(87 \%)$ and nearly half of the preinjury relationships $(43 \%)$.

Of those who were sexually active, about half of the partners in preinjury relationships $(52 \%)$ and three-quarters of the partners in postinjury relationships (78\%) 
Table III Partner ratings on VAS QL Scale, Sexual Adjustment - SIAS Scale, the Sexual Behaviour Scale and the Emotional Quality of the Relationship Scale ( $n=49$ partners)

\begin{tabular}{|c|c|c|c|c|c|}
\hline \multirow[t]{2}{*}{ Variable } & \multicolumn{2}{|c|}{$\begin{array}{l}\text { Partners in preinjury } \\
\text { relationships }(n=26)\end{array}$} & \multicolumn{2}{|c|}{$\begin{array}{l}\text { Partners in postinjury } \\
\text { relationships }(n=23)\end{array}$} & \multirow{2}{*}{$\begin{array}{c}\text { Age-adjusted } \\
\text { difference } \\
p \text {-level }\end{array}$} \\
\hline & $\begin{array}{l}\text { Mean score } \\
\text { (SD) }\end{array}$ & $\begin{array}{l}\text { Median score } \\
\quad \text { (Range) }\end{array}$ & $\begin{array}{l}\text { Mean score } \\
\quad(\mathrm{SD})\end{array}$ & $\begin{array}{l}\text { Median score } \\
\text { (Range) }\end{array}$ & \\
\hline VAS Quality of Life Rating & $\begin{array}{c}52.5 \\
(34.3)\end{array}$ & $\begin{array}{r}56.5 \\
(5-99)\end{array}$ & $\begin{array}{c}79.4 \\
(16.1)\end{array}$ & $\begin{array}{r}85.0 \\
(48-100)\end{array}$ & n.s. \\
\hline Sexual Adjustment (SIAS Scale) & $\begin{array}{l}13.8 \\
(6.7)\end{array}$ & $\begin{array}{c}14 \\
(6-24)\end{array}$ & $\begin{array}{l}22.4 \\
(3.7)\end{array}$ & $\begin{array}{c}23 \\
(14-27)\end{array}$ & n.s. \\
\hline The Emotional Quality of the Relationship Scale & $\begin{array}{l}21.6 \\
(5.0)\end{array}$ & $\begin{array}{c}23 \\
(7-28)\end{array}$ & $\begin{array}{l}23.9 \\
(3.9)\end{array}$ & $\begin{array}{r}25 \\
(15-28)\end{array}$ & n.s. \\
\hline The Sexual Behaviour Scale & $\begin{array}{l}22.8 \\
(11.9)\end{array}$ & $\begin{array}{c}24 \\
(7-43)\end{array}$ & $\begin{array}{l}40.0 \\
(7.3)\end{array}$ & $\begin{array}{r}43 \\
(25-49)\end{array}$ & $a$ \\
\hline
\end{tabular}

Quality of Life rating; range of score $0-100$.

Sexual Adjustment rating: range of raw score 6-28.

The Emotional Quality of the Relationship rating: range of raw score 7-28.

The Sexual Behaviour rating: range of score $0-49$.

$\mathrm{a}=p<0.01$ Pitman's permutation test.

n.s. $=$ non-significant . 


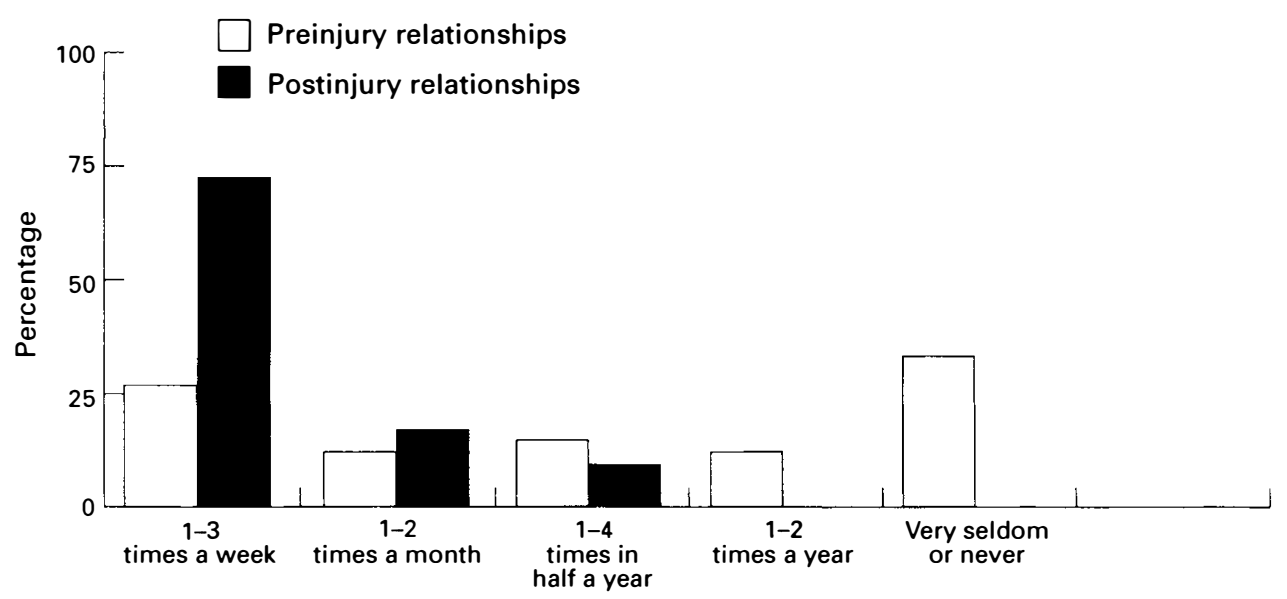

Figure 2 Frequency of sexual activity as reported by the partners ( $n=26$ preinjury and 23 postinjury partners).

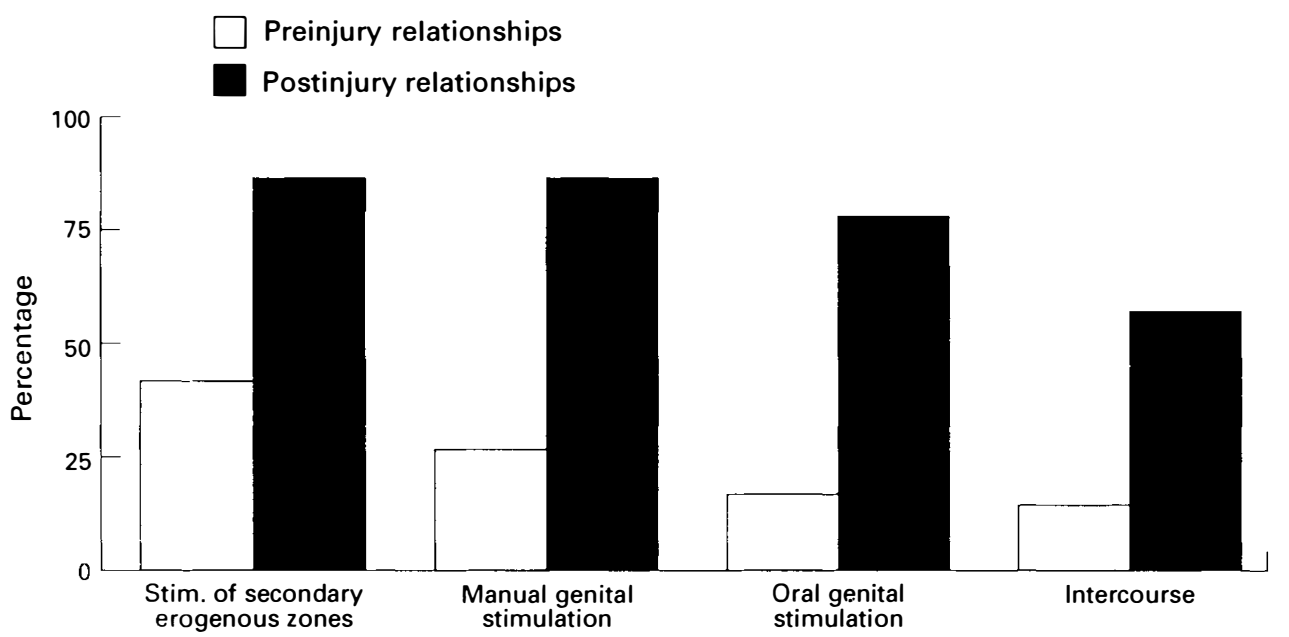

Figure 3 Relative frequency of use of various sexual expressions ( $n=26$ preinjury and 23 postinjury relationships).

experienced orgasm on most occasions during sexual interaction.

As illustrated in Table III, the mean scores of the SIAS scale and the Sexual Behaviour Scale were significantly higher among partners in postinjury relationships.

\section{Quality of life}

As shown in Table III, the mean value of the QL rating was significantly higher among partners in postinjury relationships.
Due to the large differences in age between partners as well as SCI persons in preinjury and postinjury relationships, statistical analysis with age as a covariate was used. The influence of age was responsible for most of the differences between the two groups. However, some significant differences remained. The frequency of sexual activity and the use of various sexual expressions, as measured by the Sexual Behaviour Scale, were significantly lower in preinjury relationships $(p<0.05$ and 
$p<0.01$, respectively). Furthermore, perceived deterioration of sex life due to the injury was significantly higher among preinjury partners $(p<0.01)$. In contrast, sexual adjustment as measured by the SIAS scale and the emotional quality of the relationship showed no significant differences when age was statistically controlled. All other variables addressing sexual and emotional aspects of the relationship were also found to be primarily related to the age discrepancy between the two groups. Furthermore, the partners' perception of their overall quality of life showed no difference between the two groups when the influence of age was controlled.

\section{Personality characteristics}

To investigate whether personality characteristics differed between partners in the pre- and postinjury groups or compared with a reference group, the ANOVA oneway analysis of variance was performed. As illustrated in Figure 4, no significant differences were revealed between partners in pre- and postinjury relationships, or be-

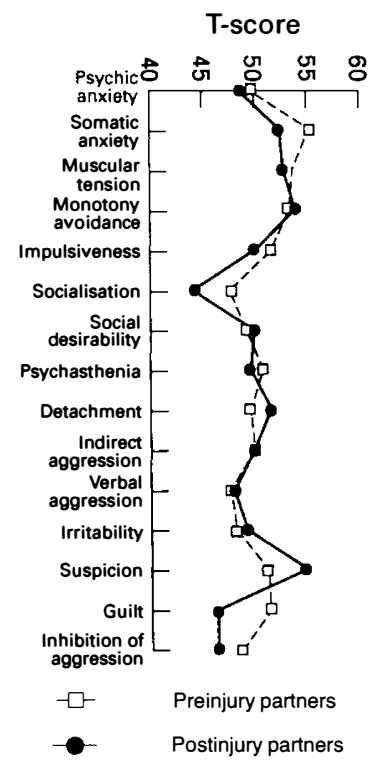

Figure 4 The partners' T-scores on the Karolinska Scales of Personality. The higher the score, the higher degree of the trait measured $(n=20$ preinjury partners and 23 postinjury partners below the age of 65 years). tween men and women. Furthermore, the partners' scores of the personality inventory differed only partly from those of a reference group (Fig 5). The partners of the SCI persons tended to have somewhat lower scores in the Socialization Scale (mean 45.36, SD 11.7, $p<0.05)$ and the Inhibition of Aggression Scale (mean 47.28, SD 10.5, $p<0.05$ ), whereas they had higher scores in the Monotony Avoidance Scale (mean 53.89, SD 9.9, $p<0.01)$.

\section{Discussion}

This study compared pre- and postinjury intimate relationships from the partners' point of view. It should be noted, however, that only those preinjury relationships that had survived the changes imposed by the injury are included. About half of the relationships existing when injury occurred had terminated. ${ }^{21}$

Although sexual activity had decreased, or even ceased, in many preinjury relationships, there were no differences between the preinjury and postinjury groups in terms of emotional attachment within the couples and satisfaction with the relationship as a whole. The role of sexuality is an important factor in intimate relationships, yet many

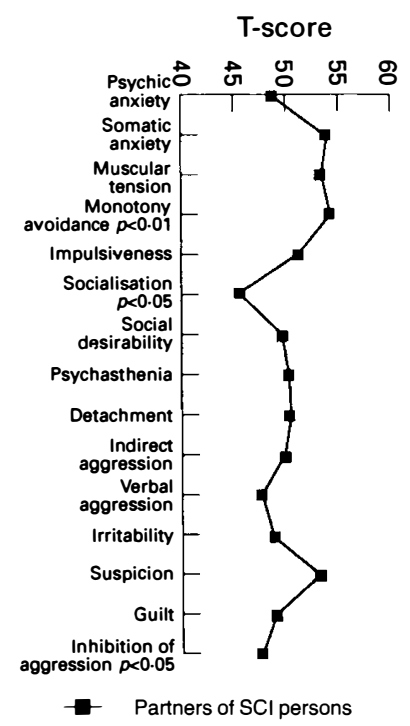

Figure 5 The partners' T-scores on the Karolinska Scales of Personality ( $n=43$ partners below the age of 65 years). 
authors have reported that the sexual relationship is not a necessary factor for a satisfying partner relationship. This holds true for people in general as well as for the person whose sex life is affected by a physical disability. ${ }^{22,23,24}$ It appears in this study that many relationships were quite satisfactory, even in the absence of sexual activity. The depth and stability that may exist in a relationship of long duration may be of greater importance than is sexual activity. This is supported by written comments from some of the respondents: 'At our age and with his disability, we consider sex of less importance' and 'there are other values in life than sex in a long-lasting relationship'.

Although most differences between the pre- and postinjury relationships studied were age-related, some were not. Those couples who had totally ceased sexual activity and those who reported having sex once or twice a year or less were all older and married before the injury. It is possible that in some of these cases the decline in sexuality is due to the normal ageing process, as was suggested by Nikas et al. ${ }^{25}$ Their study of 15 veterans, 40 years after injury, showed that nearly all had ceased sexual activity. Relatively little is known about sexual activity of healthy older individuals but the research of Masters and Johnson ${ }^{26}$ has established that sexual activity may continue into the eighth and even ninth decade. In a Swedish study, ${ }^{27}$ it was shown that half of those couples who were married still had intercourse at the age of 70 years. Considering that more preinjury than postinjury partners claimed that the decrease of sexual activity was due to the injured partner's disability, it seems that younger people and those more recently married may be more flexible and able to identify new sexual roles leading to a rewarding sex life. This is not surprising considering that younger people have grown up in a time of sexual liberation. Many of society's former taboos concerning sexuality may withhold older people from some acts of sexual expression. On the other hand, one cannot eliminate the duration of the relationships as a possible confounder. Couples in recently established relationships may have a greater sexual appetite and curiosity than couples in relationships that have lasted for many years.

Talking about sex is taboo among older people, which was confirmed in this study. Decreased sexual activity or disinterest in sex may at least partly stem from a lack of open and honest communication about sexual issues. Considering that frank and open communication between sexual partners is postitively related to the quality of their sexual relationship, ${ }^{28}$ couples should be encouraged to use frequent verbal as well as nonverbal feedback about sexual concerns.

That some preinjury partners reported deterioraton of their sex life after their partner's injury could also be referred to the fact that many of them frequently assisted their injured partner with their personal care. Partners acting as care givers might be troubled by the dual role of care giver and lover. More efforts have to be made to encourage partners not to act as care givers for their injured partner.

Fewer preinjury partners considered themselves to be sexually attractive, which may also be age-related. Preinjury couples went out of the home for social and recreational activities less often than did those in the postinjury group.

Most of the partners in postinjury relationships were satisfied with their current sex life. Half of them even considered it to be better than their previous sex life with an able-bodied partner. None of the partners in preinjury relationships gave such a response. This could be explained by the postinjury couples' use of a wider range of sexual expressions, which may be a source of greater sexual satisfaction. However, sexual adjustment, as measured by the SIAS scale, showed that once the influence of age was controlled, there was no significant difference between partners in pre- and postinjury relationships.

The perceived lower satisfaction with life among partners in preinjury relationships was also primarily related to the age discrepancy. This finding suggests that older people may be more resentful of the changes imposed on their lives by the injury than are younger people. 
It has been suggested that partners of SCI persons might have unusual qualities that contribute to the success of postinjury relationships. ${ }^{6,7,8}$ However, this study shows that there were no significant differences between pre- and postinjury partners' personality characteristics, as measured by the KSP. Furthermore, the partners'personality traits differed only partly from those of a reference group. The somewhat higher scores in the Monotony Avoidance Scale indicate a need for change and action (sensation seeking), and difficulty withstanding boredom and routine. This quality might be valuable considering the flexibility demanded by the disability. The lower scores in the Socialization Scales indicate that the partners in this study behave less according to rules and conventions. As suggested by Crewe and Krause, ${ }^{7}$ they may have 'the independence necessary to look beyond society's stereotypes concerning intimate involvement with a disabled person', and a greater acceptance of sexual variety. Finally, the lower scores in the Inhibition of Aggression Scale indicate that the partners are able to speak up and assert themselves in social situations. These special personality traits imply that partners in both pre- and postinjury relationships in this study might be somewhat more courageous and confident than the average person.

As the personality characteristics of the partners in this study differed only slightly from those of a comparable reference group and not at all between partners in pre- and postinjury relationships, we can dismiss the assumption that the partners' unusual qualities or values are the primary explanation for a spinal cord injured person's satisfactory marriage or relationship.

Concerning the sexual part of the relationship, some differences were revealed, favouring the postinjury relationships, which held true even when age was accounted for. In all other areas, the preinjury and postinjury relationships did not seem to differ. The findings support the conclusion that age seems to be a more important factor for sexual adjustment after spinal cord injury than whether the relationship is established before or after the injury.

The present results suggest that strong emphasis should be placed on sexual counselling designed to open the sexual channels by enhancing communication, sensualism and experimentation with a wide range of sexual options. Spouses and partners should be included early in this process and particular attention should be given to older couples. Counselling and information may help these couples to overcome taboos and inhibitions for a greater acceptance of a variety of sexual activites. Furthermore, booster sessions should be available repeatedly since sexually related needs and concerns might change over time. However, it is important to keep in mind when dealing with this subject that sexuality is a sensitive and private issue. In fact, the absence of sexual activity may in some cases be a form of successful adjustment.

\section{Acknowledgements}

This work was supported by grants from the Ministry of Health and Social Affairs and the Swedish Council for Social Research (No. 90-0180:1).

\section{References}

1 David A, Gur S, Rozin R (1977) Survival in marriage in the paraplegic couple: Psychological study. Paraplegia 15: 198-201.

2 Kester B, Rothblum E, Lobato D, Milhous R (1988) Spouse adjustment to spinal cord injury. Long-term medical and psychosocial factors. Rehabil Counc Bull 32: 4-21.

3 Comarr A (1962) Marriage and divorce among patients with spinal cord injury. Journ Indian Med Profession 9: 4353-4359.

4 Guttmann L (1964) Married life of paraplegics and tetraplegics. Paraplegia 2: 182-188.

5 El Ghatit A, Hanson R (1976) Marriage and divorce after spinal cord injury. Arch Phys Med Rehabil 57: 470-472.

6 Crewe N, Athelstan G, Krumberger J (1979) Spinal cord injury: A comparison of preinjury and postinjury marriages. Arch Phys Med Rehabil 60: 252-256.

7 Crewe N, Krause J (1988) Marital relationships and spinal cord injury. Arch Phys Rehabil 69: 435-438. 
8 Simmons S, Ball S (1984) Marital adjustment and self-actualisation in couples married before and after spinal cord injury. J Marriage Family Nov: 943-945.

9 Frankel H, Hancock D, Hyslop G, Melzak J, Michaelis L, Ungar G, Vernon J, Walsh J (1969) The value of postural reduction in the initial management of closed injuries of the spine with paraplegia and tetraplegia. Paraplegia 7: 179-192.

10 Cronbach L (1951) Coefficient alpha and the internal structure of tests. Psychometrica 16: $297-334$.

11 Nunnally J (1978) Psychometric Theory. 2nd edn. McGraw-Hill Inc, New York.

12 Carlsson A (1983) Assessment of chronic pain. I. Aspects of the reliability and validity of the visual analogue scale. Pain 16: 87.

13 Schalling D, Edman G, Åsberg M (1983) Biological basis of sensation seeking, impulsivity and anxiety. In: Zuckerman M, editor. Impulsive Cognitive Style and Inability to Tolerate Boredom. Erlbaum, Hillsdale, $\mathrm{NJ}: 123-145$.

14 Schalling D, Åsberg M, Edman G, Levander S (1984) Impulsivity, Nonconformity and Sensation Seeking as Related to Biological Markers for Vulnerability. Clinical Neuropharmacology. Raven Press, New York.

15 Schalling D, Cronholm B, Åsberg M, Espmark S (1973) Ratings of psychic and somatic anxiety indicants. Acta Psychiatrica Scand 49: 353-368.

16 Schalling D, Cronholm B, Åsberg M (1975) Components of state and trait anxiety as related to personality and arousal. In: Levi I, editor. Emotions, Their Parameters and Measurement. Raven Press, New York: 603-717.

17 Schalling D, Åsberg M, Edman G, Oreland L (1987) Markers for vulnerability to psychopathology: Temperament traits associated with platelet MAO activity. Acta Psychiatrica Scand 76: 172-182.

18 Schalling D, Edman G (1988) Personality and vulnerability to psychopathology: The development of the Karolinska scales of personality (KSP). (Unpublished).

19 Statistical Analysis Systems Institue (1990) Statistical Analysis System. SAS Institute, Cary, North Carolina.

20 Bradley J (1968) Distribution-free Statistical Tests. Prentice-Hall, London: 68-86.

21 Kreuter M, Sullivan M, Siösteen A (1994) Sexuality, partner relationship and quality of life after spinal cord injury. (Unpublished).

22 Hartman L (1988) The interface between sexual dysfunction and marital conflict. Am J Psychiatry 137: 576-578.

23 Patton D, Warind E (1984) The quality and quantity of marital intimacy in the marriages of psychiatric patients. J Sex Marital Ther 1: 201-206.

24 Trieschman R (1988) Spinal Cord Injuries. Psychological, Social and Vocational Rehabilitation. 2nd edn. Demos Publishers., New York.

25 Nikas V, Fleischman P, Burton P (1990) Sexual and marital adjustment of World War II spinal cord injured veterans. Paraplegia 28: 164-171.

26 Masters WH, Johnson VE (1966) Human Sexual Response. Little, Brown \& Company, Boston.

27 Persson G (1980) Sexuality in a 70-year-old urban population. J Psychosom Res 24: 335-342.

28 Snyder D (1979) Multidimensional assessment of marital satisfaction. J Marriage Fam 41: 813-823. 